\title{
A patient with mexiletine-related psychosis
}

This article was published in the following Dove Press journal:

International Journal of General Medicine

I November 201 |

Number of times this article has been viewed

Fnu Shailesh

Sandeep Singla

Ravi Sureddi

Abhishek J Deshmukh

Hakan Paydak

Division of Cardiovascular Medicine, University of Arkansas for Medical

Science, Little Rock, AR, USA

Video abstract

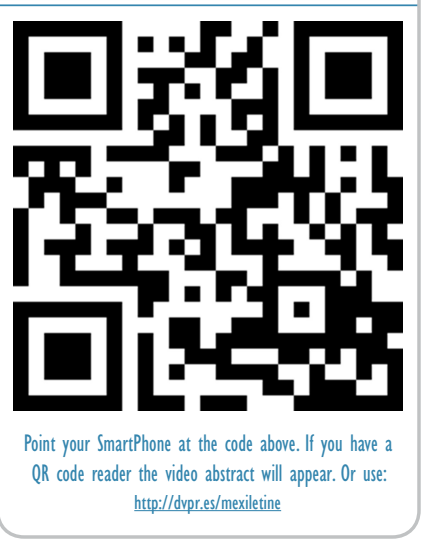

Correspondence: Abhishek J Deshmukh Division of Cardiovascular Medicine, University of Arkansas for Medical

Science, I 3500 Chenal Parkway, apt-2002.

Little Rock, AR 722I I, USA

$\mathrm{Tel}+\mathrm{I} 4145812153$

$\mathrm{Fax}+\mathrm{I} 5016866439$

Email ajdeshmukh@uams.edu
Abstract: Mexiletine is a commonly used Class IB (Vaughan William classification) antiarrhythmic drug. We report a case of mexiletine-induced psychosis that was successfully managed by decreasing the dose and using alternative medications for management of ventricular tachycardia.

Keywords: mexiletine, antiarrhythmic, psychosis

\section{Introduction}

Mexiletine is an oral congener of lidocaine, which is commonly used as a second-line agent for treatment of ventricular tachycardia. Although neurological side effects have been reported, to the best of our knowledge, this is the first case of mexiletine-induced psychosis reported in the English literature.

\section{Case report}

The patient was a 19-year-old man with a past medical history significant for surgically repaired ventricular septal defect, resected subaortic stenosis, a mechanical aortic valve, and a dual chamber internal cardiac defibrillator. About 1 year prior to his index hospitalization, amiodarone was stopped because of thyrotoxicosis and the patient was started on metoprolol $100 \mathrm{mg}$ and mexiletine $150 \mathrm{mg}$, both taken twice a day. The mexiletine dose was increased to $300 \mathrm{mg}$ twice a day because the patient continued to have runs of nonsustained ventricular tachycardia leading to antitachycardia pacing therapies. He presented to the inpatient psychiatry service 3 weeks after the dose increase, with a 2-week history of progressively increasing flat affect and delusional thoughts. Based on the clinical presentation, a diagnosis of acute psychosis was considered. There was no prior history of any psychiatric illness. There was no history of fever, and laboratory work did not show any leukocytosis. His serum electrolytes, renal and hepatic function, serum thyroid-stimulating hormone, and blood vitamin B12 levels were within the normal range. Computed tomography of the head did not show evidence of any acute intracranial process, and a urine drug screen was negative. Mexiletine was discontinued given the temporal correlation between his symptoms and the recent increase in mexiletine dose, and he was started on sotalol $120 \mathrm{mg}$ twice a day. Risperidone and haloperidol were used on an as-needed basis for control of psychotic symptoms.

On the next day, the patient's sensorium worsened and he developed catatonia. Antipsychotic medications were stopped and the dosage of sotalol was reduced to 
$80 \mathrm{mg}$ twice a day. The patient's sensorium improved after stopping the antipsychotics and decreasing the dose of sotalol. During the course of his 12-day hospital stay, his psychotic symptoms resolved. The patient was continued on sotalol $80 \mathrm{mg}$ twice a day for control of ventricular tachycardia. He was seen in the electrophysiology clinic at a 3-month follow-up visit. The patient did not have any recurrence of psychotic symptoms and his intracardiac device interrogation did not show any runs of sustained or nonsustained ventricular tachycardia. The patient is being followed up closely in our electrophysiology clinic.

\section{Discussion}

Mexiletine is a Class IB oral antiarrhythmic medication with a mechanism of action similar to that of lidocaine, and it is used for management of ventricular tachycardia. ${ }^{1}$ It is generally used in 100-300 mg doses three times a day, with a maximum recommended dose of $1200 \mathrm{mg}$ /day. Neurological side effects are common, but are usually limited to headache, insomnia, tremors, dizziness, and fatigue, and seizures have been occasionally reported. ${ }^{1}$ Most of these side effects are dose-related and resolve with dose adjustment. Psychosis has been reported previously with quinidine ${ }^{2}$ and procainamide ${ }^{3}$ (Class IA agents), lidocaine ${ }^{4}$ (a Class IB agent), and flecainide (a Class IC agent). ${ }^{5}$ Based on this case report, psychosis appears to be a dose-related side effect of mexiletine therapy, with a Naranjo probability score ${ }^{6}$ of 7 , because the patient did not have any neuropsychiatric symptoms on a dose of $150 \mathrm{mg}$ twice a day. Lidocaine is the most extensively studied Class I antiarrhythmic medication and has common neuropsychiatric side effects which appear to be dose-related. We believe psychosis and other neurological side effects may represent an effect of sodium channel blockade, because this seems to be a class effect of the Class I antiarrhythmic agents. We suggest caution during uptitration of the mexiletine dose because it may potentially lead to psychosis which can, in some circumstances, be life-threatening.

\section{Disclosure}

The authors report no conflicts of interest in this work.

\section{References}

1. Monk JP, Brogden RN. Mexiletine. A review of its pharmacodynamic and pharmacokinetic properties, and therapeutic use in the treatment of arrhythmias. Drugs. 1990;40(3):374-411.

2. Deleu D, Schmedding E. Acute psychosis as idiosyncratic reaction to quinidine: report of two cases. $\mathrm{Br}$ Med J (Clin Res Ed). 1987;294(6578):1001-1002.

3. Schubert DS, Gabinet L, Hershey LA. Psychosis induced by sustainedrelease procainamide. Can Med Assoc J. 1984;131(10):1188-1190.

4. Turner WM. Lidocaine and psychotic reactions. Ann Intern Med. 1982;97(1):149-150.

5. Ting SM, Lee D, Maclean D, Sheerin NS. Paranoid psychosis and myoclonus: flecainide toxicity in renal failure. Cardiology. 2008;111(2):83-86.

6. Naranjo CA, Busto U, Sellers EM, et al. A method for estimating the probability of adverse drug reactions. Clin Pharmacol Ther. 1981;30(2):239-245.
International Journal of General Medicine

\section{Publish your work in this journal}

The International Journal of General Medicine is an international, peer-reviewed open-access journal that focuses on general and internal medicine, pathogenesis, epidemiology, diagnosis, monitoring and treatment protocols. The journal is characterized by the rapid reporting of reviews, original research and clinical studies across all disease areas.

\section{Dovepress}

A key focus is the elucidation of disease processes and management protocols resulting in improved outcomes for the patient. The manuscript management system is completely online and includes a very quick and fair peer-review system. Visit http://www.dovepress.com/ testimonials.php to read real quotes from published authors. 